spatial orientation, that is, in the discrimination of distances and directions.

R. H. J. Watson (London) read a paper on "Stereotype Behaviour in the Rat". Such behaviour is one of many kinds often called abnormal which are conveniently studied in the rat. Mr. Watson considered in detail the difficulties encountered in arriving at criteria for normality and abnormality of behaviour. He considered in particular the suggestion made by Maier that behaviour should be considered normal if it were predictable from learning theory, abnormal otherwise. Using this criterion, Maier claimed that stereotype behaviour was abnormal, instigated by frustration resulting from presenting the rats with an insoluble problem. Mr. Watson reported experiments in which a more complex insoluble problem was used and in which a more complex stereotyping resulted. The analysis of the results indicates that, both in the insoluble problem and in a subsequent soluble problem, the behaviour conformed on a number of criteria to that which would be predicted from conventional learning theory. The results also suggested that such stereotypes would be self-perpetuating.

H. B. M. Hurwitz (London) read a paper, "Response Patterns in the Rat", which was also concerned with the predictive value of learning theory. In learning theories, it is commonly assumed that the strength of a response is a function of habit strength together with drive strength. The favourite experimental devir = for investigating the roles of these two factors is the Skinner box, in which rats learn to depress a lever to obtain delivery of food in a food trough. When the habit has been learnt, food is withheld and a count made of the number of lever-pressings produced before the habit is extinguished. Data obtained in this way are of basic importance to the theories of Hull and Skinner, for example. Mr. Hurwitz reported experiments using a modified Skinner box (which he demonstrated) with which the temporal and serial patterning of responses (both at the food trough and the lever) could be observed. Analysis of results suggested that the postulation of a secondary drive, frustration, could best explain the behaviour of the rat during extinction of the habit. Evidence for this would not have been forthcoming if conventional methods of analysing responses had been used.

General discussions on the papers were introduced by Profs. R. W. Russell (London) and W. S. Verplanck (Harvard). There were detailed discussions on methodology of the individual researches reported; more general topics covered included behavioural differences between various strains of rats, the use of the concept 'abnormal', and the predictive value of learning theories.

B. M. Foss

\section{CAREERS IN CHEMICAL ENGINEERING}

$\mathrm{A}^{\mathrm{N}}$ $\mathrm{N}$ unexpected occurrence during the past few years has been the large decline in the numbers of men seeking admission to the universities for training as engineers, a decline noted not only in Britain but also to an even greater extent in the United States. Simultaneously, committee after committee has urged the need for more engineers in general, and chemical engineers in particular. Extensive training schemes will obviously be of little value unless the numbers of those willing to be trained can be greatly increased, and thus the issue by the Institution of Chemical Engineers of a small brochure entitled "Careers in Chemical Engineering" is most opportune (pp. $12+4$ plates. Irist. Chem. Eng., 56 Victoria Street, London, S.W.1, 1953 ; 2s.). This explains clearly, in the simplest language, what chemical engineering is, how it developed, what a chemical engineer does, his opportunities, and how he can be trained; and it supplements its descrip. tions with admirable illustrations of plant of diverse nature, designed and constructed by chenical engineers. It is to be hoped that means will be found of bringing this pamphlet to the notice of every schoolboy leaving school, every schoolmaster, and every man at present engaged on National Service.

Modesty, unfortunately, seems to have compelled the authors to refrain from mentioning, except in the vaguest terms, the remuneration a chemical engineer may expect; in this materialistic age, one of the first questions asked by a young man selecting a career is: "What salary shall I get and what are the prospects ?" This aspect might well be amplified in a future edition. A further line of thought is aroused by the almost parenthetical mention of teaching as an outlet for chemical engineers. Every academic member of the profession knows only too well the extreme scarcity of good teachers, and this fact must be regarded at the moment as the bottleneck in any scheme for the large expansion of chemaical engineering training in Britain. Until steps are taken to induce a far larger proportion of chemjeal engineers than at present to go in for teaching, any increase in the numbers seeking training, or in funds for laboratory extensions, will be rendered of little avail.

H. E. WATSON

\section{WOOL INDUSTRIES RESEARCH ASSOCIATION

$$
\text { REPORT FOR 1952-53 }
$$

$T$ HE report for 1952-53 of the director of research of the Wool Industries Research Association* records that the opening of new research laboratories at the Leeds headquarters of the Association has greatly increased the research potential. Three new blocks of laboratory buildings, erected since the end of the Second World War, were officially opened by Lord Swinton in October last year. With a staff now totalling 203, a very considerable variety of research topics has been and is being examined, ranging from ad hoc investigations of a purely consultative type, designed to assist industrialists in solving the dayto-day problems of a highly technical industry, to almost purely mathematical analyses of the system of forces acting upon fibre arrays during roller drafting, and of the corresponding and resulting fibre displacements.

Among the many research activities mentioned in the director's report, several are noteworthy for the ingenuity and modernity of the techniques employed. For example, in order to test the theory of carding which has been developed at the Association, an electrical counterpart or analogue of the three-part scribbler has been built. This shows in electrical terms what happens to a discontinuous feed, such as is obtained from the hopper of a card, as it passes

* Wool Industries Research Association. Report of the Director of Research for 1952-53 (Publication No. 196). Pp. 27. (From the Association, Leeds, 1953.) 
through a scribbler of up to three swifts, and with one or more workers and strippers per swift. The device can also be used for predicting the effect of automatic controllers on the behaviour of the card, particularly in respect of possible hunting of the proposed control. This application of electronic computer techniques must mean the saving of much valuable time, to say nothing of the large amounts of actual raw material which would otherwise have to be processed to obtain the required results.

Fibre movement in roller drafting has been studied with the aid of radioactive tracers, the principle being to mix at random into a sliver a certain proportion of labelled fibres, and then to follow the movement of these fibres in the body of the sliver as it passes through successive drafting operations by standard procedures.

In the biological field, work on the identification of fibres by use of the sequence in cuticular scale pattern along the lengths of the fibres has led to a new classification of scale patterns for general use and has given more sensitive criteria for the identification of fibres. Such work may well have valuable applications outside the textile field-for example, in forensic science.

While the above examples may perhaps be cited as outstanding features of the Association's research programme, they are accompanied by a very great deal of less spectacular, but nevertheless invaluable, work of a routine nature.

The problem remains, and is recognized as fundamental by all workers in technological research, of getting the results obtained in the laboratory translated as rapidly as possible into practice in industry. The textile industry is probably no more backward in this respect than others; but it certainly remains true that much information which could, if thoroughly applied, make a very great difference to the technical efficiency of the industry, remains literally a closed book so far as the latter is concerned. This is not necessarily due to any strong prejudice against scientific research, but rather to the difficulty of securing adequate liaison between laboratory and the mill. The Wool Industries Research Association has made a notable attempt to surmount this difficulty by the appointment of liaison officers for this sole purpose. To quote the report on this matter : "The officers' visits give contributory members the advantage of verbal amplification of the Association's publications, and the advantage of discussing the firm's particular problems on the spot. At the same time these discussions enable the officers to keep the Association's staff informed of contemporary conditions and developments in the industry; thus research work can be directed along the most beneficial lines. Points of interest to members are discussed which often result in an investigation being pursued, to the members' very considerable advantage. The officers are also able to arrange for the co-operation of member firms in experimental projects which require large-scale trials or surveys. This two-way passage of information and of the use of equipment was scarcely anticipated when the liaison officers were appointed, but there is no doubt that it is now a valuable feature of their activities".

Such schemes of interchange are, of course, by no means novel in the industry, and are shared by other research associations and by university departments; but it is heartening for those whose foremost aim is the technical betterment of industry through sound research to see the process enlarged.

\section{THE FRAMEWORK OF ASTRONOMY}

FoR his inaugural lecture as Perren professor of $f$ astronomy in the University of London, which he gave last year at University College, London, Prof. C. W. Allen chose as his subject "The Framework of Astronomy". At the beginning of this lecture, which has now been published*, Prof. Allen points out that the work of the astronomer usually falls into one or the other of two categories: the expanding category, in which are the activities of elaborating, detailing, compiling and investigating individual objects for their own sake; and the contracting category, which includes the work of unifying, consolidating and standardizing. Very appropriate analogues are found in the political realm-namely, individualism and freedom in the first category, and regimentation and good order in the second. Both approaches are necessary in astronomy. The expanding individualism leads to new ideas and discoveries and also to long observational programmes with their risk not only of drudgery but also of the absence of discovery; equally important, however, is the regimentation mentioned under the contracting category, in which the co-ordination of the original facts and even, if required, the addition of missing links, tend to strengthen the subject. Such coordinated results frequently reveal not only regularities but also departures from anticipated laws, and the work of consolidation is responsible for results which can be used as a basis for further advances. The interconnexion of consolidated results from different branches of astronomy should lead to a strong stable framework of astronomical knowledge on which the future can build, and a great part of Prof. Allen's lecture is devoted to a consideration of the relation between the framework and the subject as a whole and also of the problems of constructing and using this framework. For the purpose of the lecture the following definition of 'framework' is given : "It is a complete assemblage of interconnected basis facts and quantities of astronomy prepared in readiness for use". It is admitted that no such framework exists; but as the possibility of its existence is not excluded, Prof. Allen discusses it under the above form.

An efficient framework for astronomy would contain information that represents it as a whole rather than the results of particular individuals and would be "concise, factual, and quantitative". An example is taken from the case of a comet. As every computer of cometary orbits knows, from at least three observations over about a week an orbit is computed on the assumption of parabolic motion and from this an approximate ephemeris enables observers to find it for a few weeks. Subsequent observations provide the data for a more accurate orbit, including the eccentricity, to be computed; then finality can be obtained when all the observations (probably extending over several months) are published and, taking planetary perturbations into consideration, a definitive orbit is computed. No improvement is possible with existing observations; but on the comet's next return the procedure could be repeated, and the sets of elements obtained, which represent the definitive orbits, then approach the ideal for the

* The Framework of Astronomy : an Inaugural Lecture delivered at University College, London, 1 May 1952. By C. W. Allen, Perren Professor of Astronomy in the University of London. Pp. 17. (Published for the College by $\mathrm{H}$. K. Lewis and Co., Ltd., 1952.) 38 . 